\title{
BMJ Open Association between spatial accessibility to fire protection services and unintentional residential fire injuries or deaths: a cross-sectional study in Dallas, Texas
}

\author{
Soojin Min, ${ }^{1}$ Dohyeong Kim, ${ }^{2}$ Chang Kil Lee ${ }^{3}$
}

To cite: Min S, Kim D, Lee CK. Association between spatial accessibility to fire protection services and unintentional residential fire injuries or deaths: a cross-sectional study in Dallas, Texas. BMJ Open 2019;9:e023780. doi:10.1136/ bmjopen-2018-023780

- Prepublication history for this paper are available online. To view these files, please visit the journal online (http://dx.doi org/10.1136/bmjopen-2018023780).

Received 2 May 2018 Revised 30 March 2019 Accepted 17 April 2019

A) Check for updates

C Author(s) (or their employer(s)) 2019. Re-use permitted under CC BY-NC. No commercial re-use. See rights and permissions. Published by BMJ.

${ }^{1}$ Division of General Pediatrics, Boston Medical Center, Boston, Massachusetts, USA

${ }^{2}$ School of Economic, Political and Policy Sciences, University of Texas at Dallas, Richardson, Texas, USA

${ }^{3}$ Department of Urban Policy and Administration, Incheon National University, Incheon, The Republic of Korea

Correspondence to

Dr. Chang Kil Lee;

leechangkil@yahoo.com

\section{ABSTRACT}

Objectives In addition to neighbourhood characteristics encompassing racial composition, socioeconomic status and housing environments, it was unclear if location characteristics relating to the accessibility of fire protection services were risk factors for unintentional residential fire-related injuries in urban areas. This study was aimed to measure spatial accessibility to fire protection services at the census block group level, and examine whether it is associated with unintentional residential fire-related injuries.

Design A cross-sectional study.

Setting Unintentional residential fire incidents between 2012 and 2015 in Dallas City, Texas, USA.

Main outcome measures Using multiple logistic regression, the study analysed association between unintentional residential fire incidents in the city and risk factors, including spatial accessibility to fire protection services, measured by the two-step floating catchment area method.

Results Compared with incidents without any injuries, fire incidents involving injuries were significantly more likely to include unconfined fire, fire originating in a cooking area, a bedroom for less than five people or a common family area, census block groups with $>75 \%$ African American residents, $>25 \%$ elderly single-person households and positive population growth rates $<25 \%$ or $>25 \%$. Incidents involving injuries were significantly less likely to occur in areas with high spatial accessibility, as measured by spatial accessibility score.

Conclusions In addition to fire characteristics and neighbourhood demographics, spatial accessibility to fire protection services was significantly associated with unintentional residential fire-related injuries. The findings can be used to help select locations of additional fire stations.

\section{INTRODUCTION}

While numerous demographic, socioeconomic, housing and behavioural risk factors for unintentional residential fire-related injuries or deaths have been investigated, ${ }^{1}$ insufficient attention has been paid to poor
Strengths and limitations of this study

- This study newly identified spatial accessibility to fire protection services as a major risk factor for unintentional residential fire-related injury or death.

- This study incorporated the dimensions of both demand and supply capacity of fire protection services when measuring accessibility using the two-step floating catchment area method.

- Fine spatial resolution for spatial accessibility was obtained by using census block groups rather than census tracts or Zip Codes that were used by similar studies.

- The severity of injury, including and up to death, was not distinguished due to a considerably small number of cases resulting in injury or death. Thus, the analysis focused exclusively on whether or not a residential fire involved injury or death.

- This study was unable to take into account individual characteristics of firefighting apparatus or size of firefighting staff that is likely to be varied among adjacent cities when estimating spatial accessibility from population centres located near the study area border.

accessibility to fire protection services as a risk factor. Elderly, young children and minorities-particularly African Americans-have historically been groups vulnerable to residential fires. ${ }^{23}$ Low socioeconomic status-related risk factors such as low income, large families, single parents, low levels of education and unemployment were also found to be correlated with residential fire injuries. ${ }^{4}$ Housing environment risk factors reflecting low income such as renting rather than owning a home, old housing structures, substandard living conditions, crowding or prevalence of mobile homes were reported. ${ }^{2}$ Behavioural factors were also highlighted as significant risk factors. Fatal residential fires were more likely to occur when smoking, alcohol 
intoxication or faulty smoke detectors were involved. ${ }^{356}$ The use of functioning smoke detectors has been found to contribute significantly to a decrease in the rate of house fire injuries and deaths. ${ }^{2}$

Studies have reported an association between health outcomes and neighbourhood characteristics including racial composition, socioeconomic status and housing environment. ${ }^{78}$ Similarly, studies on unintentional residential fire-related injury or death have used an ecological approach and assessed risk factors using census tracts or counties, particularly in urban areas. ${ }^{29}$ In addition to the demographics of its residents, an urban neighbourhood's geographic location also constitutes its distinct characteristics, exemplified by different levels of accessibility to various types of private and public services such as grocery stores, hospitals, parks, schools or public safety services. Accessibility to services can be indicated by a number of different measurements including travel impedance (ie, distance or time), ratio between supply and demand of services or spatial accessibility to services that takes into account both aspects. ${ }^{10}$ Disparity in spatial accessibility to services that are closely related to health outcomes such as grocery stores and medical care facilities has been widely researched. ${ }^{10-12}$

Previous research has highlighted a key role of accessibility to fire protection services-response distance or time from fire stations-in mitigating fire damages, whereby prolonged response times may enlarge the scope of the fire that can contribute to more fire injuries or deaths. ${ }^{1314}$ However, other factors in the supply chain of fire protection services, such as the balance in demand and capacity may play a role in determining the effectiveness of fire protection service delivery. More precisely defined and multidimensional measures of accessibility to fire protection services would be beneficial for investigating the connection between location characteristics of neighbourhoods and residential fire-related injury or death.

This study aims to measure spatial accessibility to fire protection services at the census block group level using the two-step floating catchment area (2SFCA) method as location characteristics of neighbourhoods, and to examine whether it is associated with unintentional residential fire-related injuries or deaths in Dallas City, Texas. Our approach enables controlling for location characteristics of neighbourhoods, and allows for the identification of relatively vulnerable areas, which can be valuable information to city management's decision-making process for locating additional fire protection services.

\section{METHODS}

\section{Study area and data sources}

The study area is Dallas City in Texas, which in 2014 suffered $>50 \%$ of the structure fires in Dallas County, the county with the highest number of structure fires in the state. ${ }^{15}$ There were 57 fire stations between 2012 and 2014, with the 58th station added in 2015 . While each of these stations has a fire engine, which pumps water, not every station has a fire truck, which supports firefighting activities by carrying ladders and other equipment. ${ }^{16}$ Since a fire engine is a critical firefighting apparatus, the service capacity of fire stations was uniformly set to be one across the city. Figure 1 shows a map of census block groups in seven city service areas (Northeast, North central, Northwest, Central, Southeast, South central and Southwest) of Dallas City showing distribution of 58 city fire stations, which illustrates that fire stations are generally located in densely populated areas.

Demographic and socioeconomic information at the census block group level from 2015 American Community Survey (ACS) 5-Year Estimates ${ }^{17}$ were used, with population data dating back to 2010. The data include 1020 census block groups within the city with population and housing unit number greater than zero. Annual public fire incident data, derived from the US National Fire Incident Reporting System, was obtained from the US Fire Administration. ${ }^{18}$ From 2012 to 2015, residential fire incidents that occurred unintentionally in Dallas City and reported with addresses that could be geocoded were investigated. Incendiary fires and fires with causes unknown or under investigation were excluded. Incidents in residential one- or two-family homes and multifamily dwellings such as apartments, condos or townhouses with no commercial use were selected. Among commercially used residential buildings, only long-term residential dwellings such as assisted-care housing facilities were included; nursing facilities and other commercial properties were not included. In all, 2142 incidents including 60 cases involving injuries or deaths were identified. Since there were only seven cases reporting deaths, injuries and deaths were not distinguished in this study.

\section{Patient and public involvement}

The study used existing public data, and there was no patient and public involvement throughout the study.

\section{Spatial accessibility: applying the two-step floating catchment area method}

Spatial accessibility to service sources, which has often been applied in examining access to healthcare, is a measurement of the spatial connection between supply and demand of services (availability represented by the service capacity-to-population ratio) taking into account travel distance or time (proximity), particularly in the context of urban areas. ${ }^{101920}$ The 2SFCA method and its modified versions such as the enhanced two-step floating catchment area method, modified two-step floating catchment area model and integrated floating catchment area method have been widely used primarily to measure spatial accessibility to primary care service providers. ${ }^{121-23}$

As a special case of gravity models that consider a service provider in a closer range to be more accessible than a more distant one, the 2SFCA method captures interactions between supply and demand of services in and out of discrete geographic boundaries, such as ZIP 


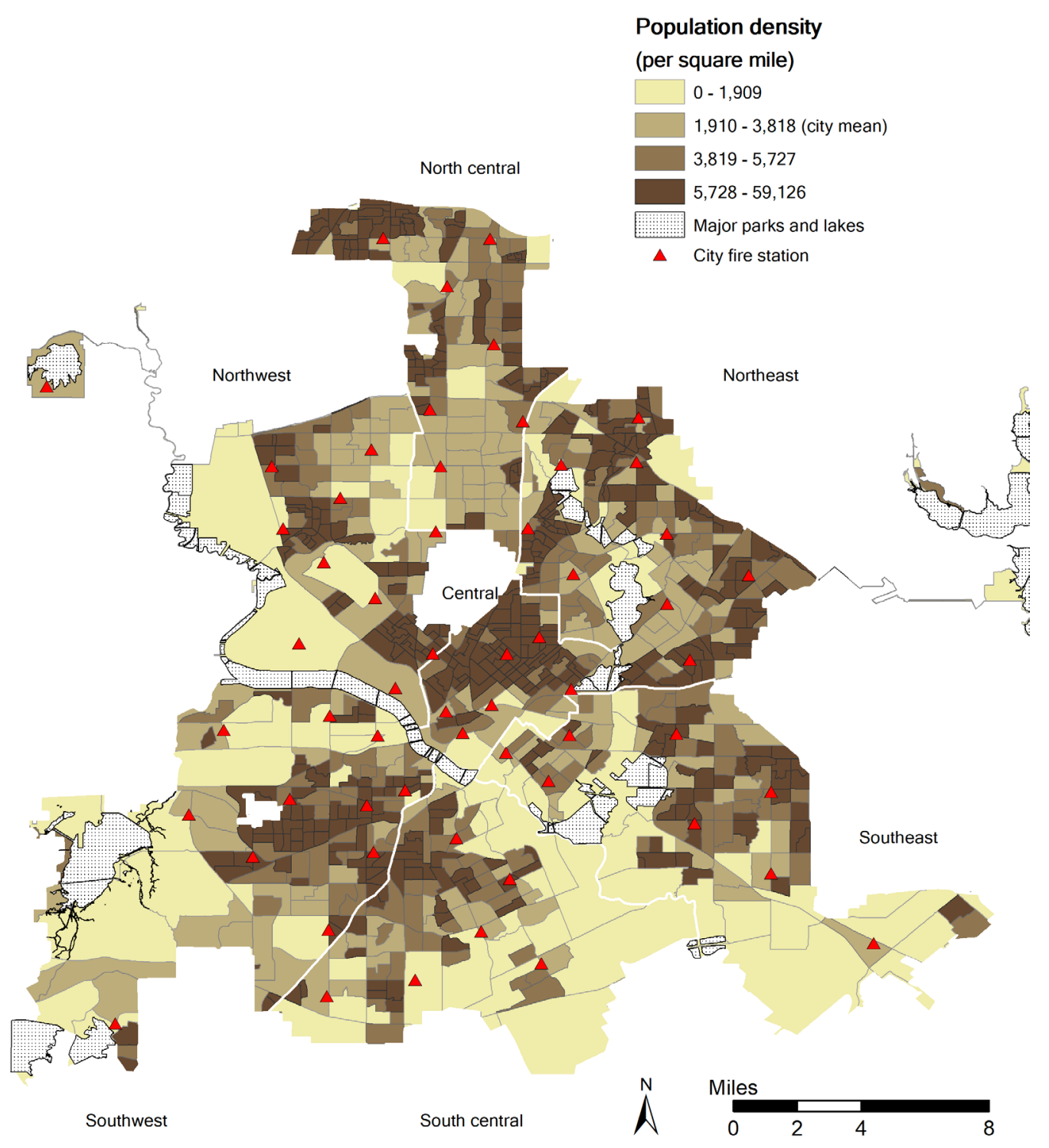

Figure 1 Distribution of city fire stations and population density across seven service areas in Dallas City, Texas, in 2015.

codes or counties, by using floating catchment areas instead of provider-population ratios (PPRs) in each discrete census unit. ${ }^{24}$ Circular catchment areas defined by a chosen maximum travel impedance-either time or distance-float from one population centre to another, and occasionally overlap with each other. ${ }^{21}$ As a result, 2SFCA provides a fine spatial resolution for measurements of spatial accessibility to services, which thus enables the identification of varied patterns in spatial accessibility. 2SFCA consists of two steps that determine service provision capacity at a service catchment area and spatial accessibility at a population catchment area, respectively ${ }^{2124}$ :

Step 1: For each service provider location $j$, search all population locations $(k)$ that fall in a catchment area at $j$ that is determined by maximum travel impedance $\left(d_{k j} \leq d_{\max }\right)$. Find $P_{k}$, population at a location $k$, and $S_{j}$, the volume of service providers in a catchment area $j$. The PPR $R_{j}$ within a service catchment area can be calculated as follows:

$$
R_{j}=\frac{S_{j}}{\sum_{k \in\left\{d_{k j} \leq d_{\max }\right\}} P_{k}}
$$

Step 2: For each population location $i$, search all service provider locations ( $j$ ) that fall in a catchment area at $i$ that is determined by the same travel impedance. A population location's spatial accessibility $A_{i}$ can be obtained by summing up $R_{j}$ within a population catchment area. Each catchment area around a population location captures a sum of service capacity of providers within the area.

$$
A_{i}=\sum_{j \in\left\{d_{i j} \leq d_{\max }\right\}} R_{j}
$$

When the 2SFCA method is applied to evaluate spatial accessibility to primary care services, well-known limitations include the same catchment area size for all populations and services, and an assumption that distance-decay 
Table 1 Multiple logistic analysis: association between risk factors and unintentional residential fire incident involving injury or death $(n=2142)$

\begin{tabular}{|c|c|c|c|c|}
\hline Risk factor & & Model1 & Model 2 & Model3 (SE) \\
\hline \multirow{6}{*}{ Fire factors } & $\begin{array}{l}\text { Fire at night time } \\
\text { Fire originated area }\end{array}$ & -0.13 & -0.11 & $-0.08(0.32)$ \\
\hline & Cooking area & $1.34^{\star *}$ & $1.36^{\star \star}$ & $1.34(0.39)^{\star \star}$ \\
\hline & Bedroom for less than five people & $1.44^{\star *}$ & $1.45^{\star \star}$ & $1.51(0.43)^{\star \star}$ \\
\hline & Heat sources & & & \\
\hline & Operating equipment & 0.13 & 0.11 & $0.11(0.36)$ \\
\hline & Open flame or smoking materials & 0.22 & 0.19 & $0.17(0.44)$ \\
\hline \multirow[t]{2}{*}{ Socioeconomic factors } & Rate of African American residents (>75\%) & 0.32 & 0.50 & $0.69(0.33)^{\star}$ \\
\hline & Rate of one-person households $>64$ years $(>25 \%)$ & $1.33^{* *}$ & $1.62^{\star \star \star}$ & $1.59(0.53)^{\star \star \star}$ \\
\hline \multirow[t]{2}{*}{ change factors } & $0 \%-25 \%$ & - & $1.10^{\star \star \star}$ & $1.07(0.35)^{\star \star \star}$ \\
\hline & $>25 \%$ & - & $1.32^{\star \star \star}$ & $1.32(0.41)^{\star \star \star}$ \\
\hline Spatial accessibility & Spatial accessibility score & - & - & $-0.11(0.06)^{*}$ \\
\hline $\begin{array}{l}\text { Akaike Information } \\
\text { Criterion }\end{array}$ & & 527.2 & 516.7 & 514.4 \\
\hline
\end{tabular}

${ }^{\star} \mathrm{p}<0.05 ;{ }^{* \star} \mathrm{p}<0.001 ;{ }^{* * *} \mathrm{p}<0.01$.

effects associated with use of services-decay in using services with increasing travel time or distance-is ignored within a catchment. ${ }^{21}$ However, these limitations may not matter in this study when examining spatial accessibility to fire protection services due to the supply and demand characteristics unique to fire protection services. While consumers of healthcare services choose to travel to service providers from their residences, fire protection service providers themselves must travel to assigned consumer locations to respond to fire incidents. Additionally, a residence relatively far from a fire station does not imply any less demand or need for fire protection services. Therefore, we argue that the assumption of the 2SFCA method where distance-decay effects are absent in a catchment area is appropriate.

Moreover, a uniform catchment area size for all populations and services can in this case be acceptable. Fire responding units are dispatched based on closest proximity in Dallas City, ${ }^{25}$ and National Fire Protection Association (NFPA) standards state that the first unit must arrive to an incident location within 4 min travel time. ${ }^{26}$ This can be used as guidance for maximum travel impedance for the nearest fire station's catchment areas. With a speed limit of $30 \mathrm{mph}$ in urban districts indicated by the Texas Transportation Code, ${ }^{27} 4 \mathrm{~min}$ travel time is equivalent to 2 miles of Euclidean distance, which is approximated to be 2.22 miles of road distance by using the optimal Minkowski coefficient $1.54 .^{28}$ Since $95.4 \%$ of the fire incidents examined in this study showed no more than 2.22 miles of road travel distance between the incident location and its nearest fire station, circular catchment areas with a 2-mile Euclidean radius were used as threshold travel distance for first responders recommended by the NFPA standard. This does not necessarily mean that fire fighters do not travel beyond this distance. Two-mile-radius circles were set as catchment areas to compare spatial accessibility to fire protection services among the census block groups under typical circumstance.

Since Dallas City has mutual aid agreements with surrounding cities, city fire stations and volunteer fire departments in 19 adjacent cities were taken into account when estimating spatial accessibility from population centres located near city borders.

Similar to studies employing the 2SFCA method to assess spatial accessibility to healthcare services, this study relied on data at the census block group level, which is the most granular unit publicly released with census demographic and socioeconomic data. ${ }^{29} 30$ Using Esri's ArcGIS 10.4, 2SFCA was applied to measure spatial accessibility ${ }^{31}$ to fire protection services based on centroids of census block groups and locations of fire stations in the study area. As the size of census block groups in the study area was sufficiently small, geographic centroids were used instead of population-weighted centroids. Geocoding was carried out by using the Census Geocoder. ${ }^{32}$ Spatial accessibility index scores were defined as obtained spatial accessibility to fire protection services for census block groups, with the service capacity (defined as number of fire engines) of each fire station set to 1 and then multiplied by 100000 . The index ranged from 0 to 20.3 across the city. 


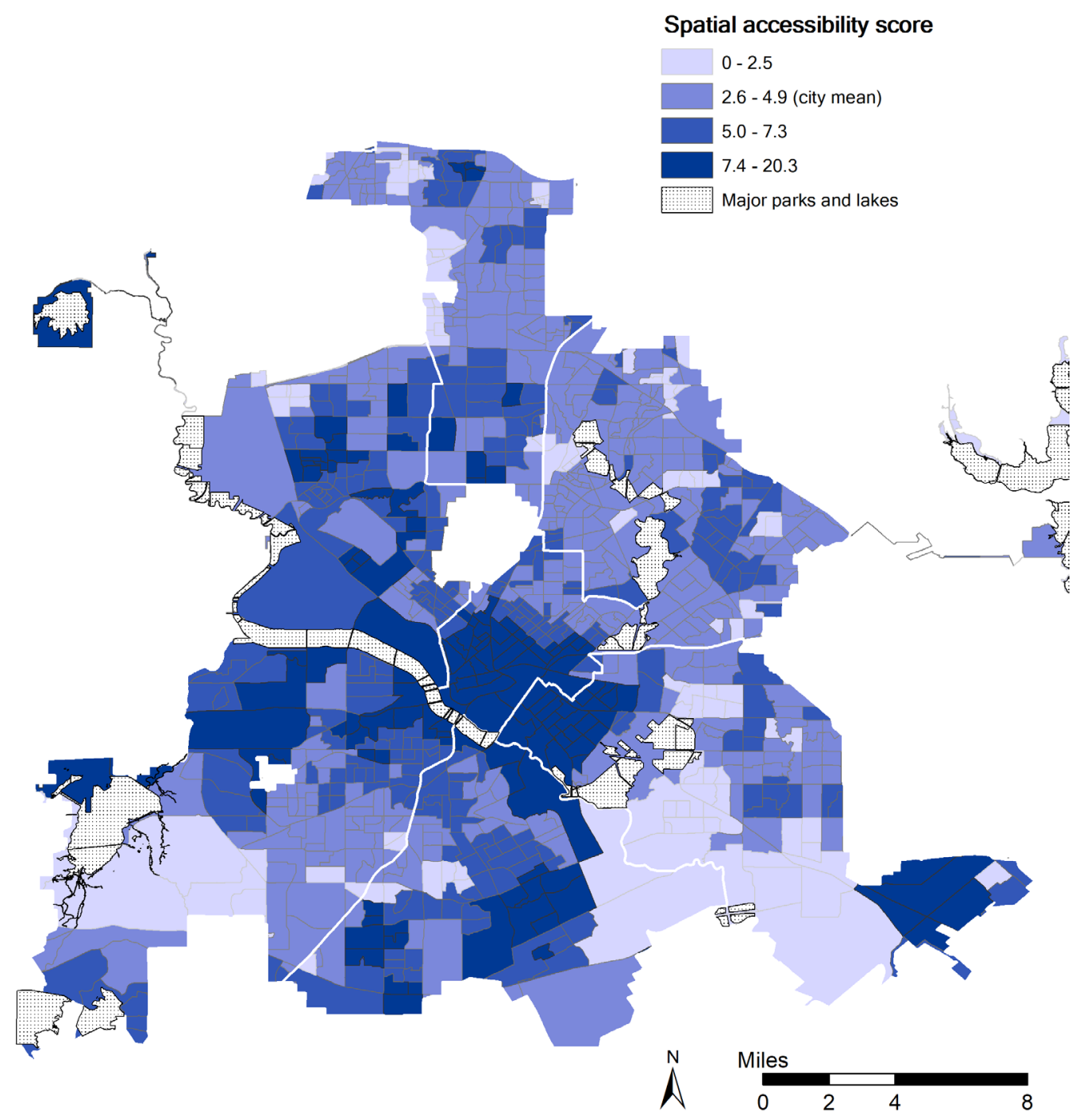

Figure 2 Distribution of spatial accessibility to fire protection services at the census block group level.

\section{Statistical analysis}

A multiple logistic regression analysis was used to examine which variables were independently associated with fire-related injury or death. The outcome variable was whether an unintentional residential fire incident involved any injuries or deaths. Initial independent variables included fire characteristics: fire origination area, heat sources, whether the fire occurred at night and whether the fire was unconfined. Heat source indicated whether a fire's heat was driven by open flame; smoking materials including cigarettes and candles; operating equipment including spark, ember, flame and electrical arcing or by other sources. An unconfined fire referred to a fire that was not contained at the object of origin. ${ }^{33}$ Night-time fires are those whose alarms were received between 10:00 pm and 6:00 am. Also, demographic and socioeconomic factors at the census block group level were included, such as $>75 \%$ non-Hispanic African American residents, $>25 \%$ singleperson households over the age of 64 and $>25 \%$ percent recently built structures (after 2000). This aligns to findings in other studies, where African American and elderly populations along with old housing structures were indicated as significant risk factors for residential fire injuries or deaths. ${ }^{215} 34$ As seen in table 1, unconfined fire, fire origin area and $>25 \%$ elderly single-person households were statistically significant $(p<0.05)$ in the initial model. For the subsequent models, population change rates and spatial accessibility to fire protection services were added. Data analysis was carried out using R V.3.3.3.

\section{RESULTS}

Spatial accessibility to fire protection services within a 2 mile radius from each census block group in 2015 is shown in figure 2 . While a minimum population-to-provider ratio of $3500: 1^{35}$ has been used to identify physician shortage areas for primary care service, there is no standard way to determine such ratio for providing fire protection services. Accordingly, interpretation of the distribution of spatial accessibility should be made in relative terms. While the spatial accessibility index scores ranged from 0 to 20.3 within the city, the citywide mean 


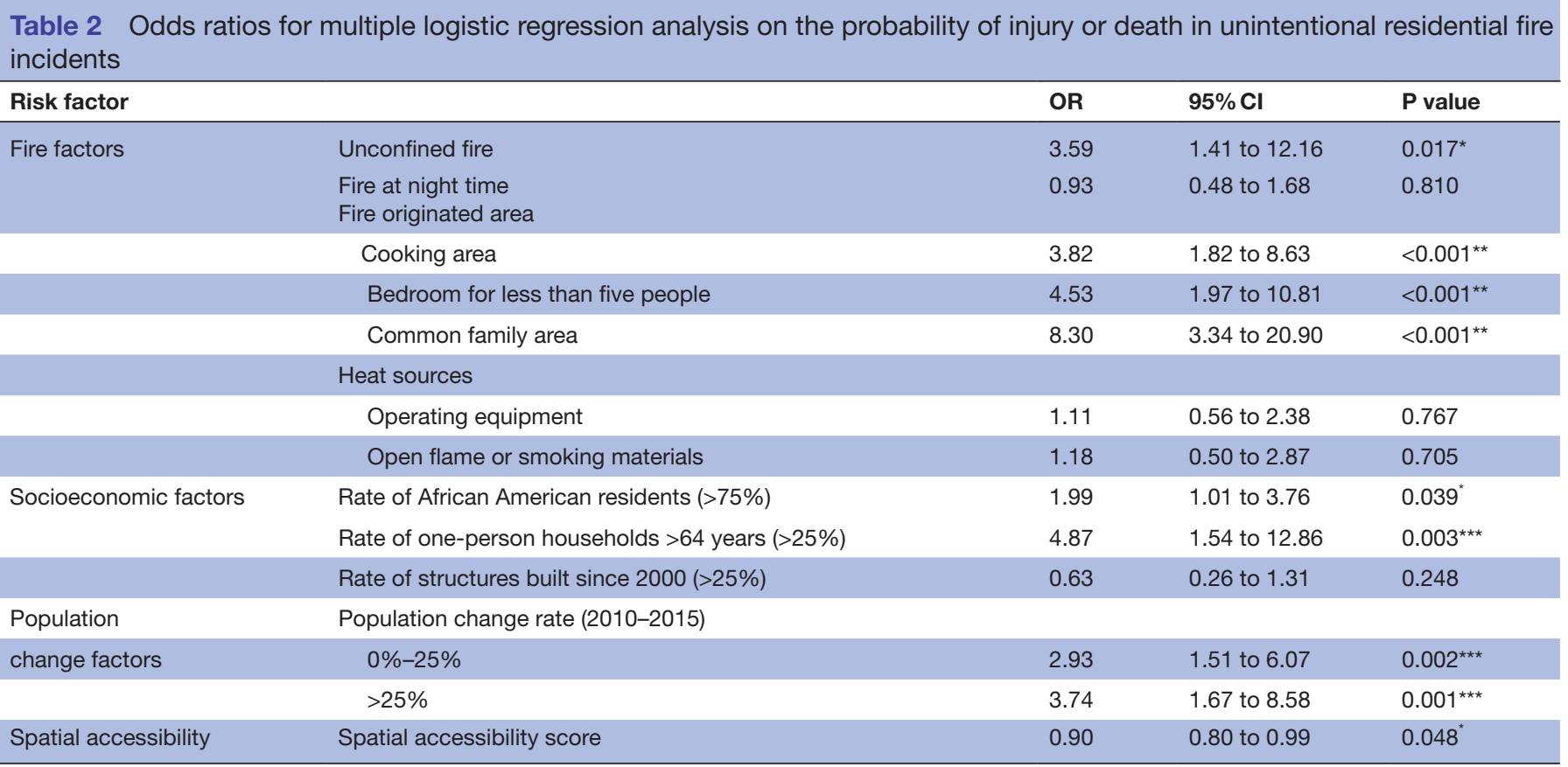

${ }^{*} \mathrm{p}<0.05 ;{ }^{* *} \mathrm{p}<0.001$; ${ }^{* \star *} \mathrm{p}<0.01$; Likelihood ratio $\chi^{2}=60.96, \mathrm{df}=13, \mathrm{p}<0.001$; Pseudo $\mathrm{R}^{2}=0.11$ (McFadden); Hosmer-Lemeshow $\chi^{2}=9.77, \mathrm{df}=8, \mathrm{p}=0.28$; maximum variance inflation factor $=1.07$.

was 4.9. Areas with relatively low spatial accessibility (index score below the city mean) mostly appeared in the southwest, southeast and northeast parts of the city.

Table 1 summarises the multiple logistic regression analysis. In model 2 , average population change rate between 2010 and 2015 was added, which demonstrated a statistically significant positive association with residential fire-related injury $(p<0.01)$. When index score of spatial accessibility to fire protection services was added to model 3 , this also showed a significant association $(p<0.05)$, this time a negative association. In this model, the rate of African American residents was also found to be a significant predictor $(\mathrm{p}<0.05)$. Its model fit improved $\left(\chi^{2}=4.29\right.$, $\mathrm{df}=1, \mathrm{p}<0.05)$. Using model 3, table 2 shows the probability of injury or death in unintentional residential fire incidents. It indicates that fire factors including unconfined fire ( $\mathrm{OR}=3.59$ (95\% CI, 1.41 to 12.16)), fire origination in a cooking area $(\mathrm{OR}=3.82(95 \% \mathrm{CI}, 1.82$ to 8.63$))$, a bedroom for less than five people $(\mathrm{OR}=4.53(95 \% \mathrm{CI}, 1.97$ to 10.81$)$ ) and common family area (OR=8.30 (95\% CI, 3.34 to 20.90)) were significant independent predictors. Neighbourhood factors at the census block group level such as $>75 \%$ African American residents ( $\mathrm{OR}=1.99$ (95\% CI, 1.01 to 3.76$)$ ), $>25 \%$ single elderly person households ( $\mathrm{OR}=4.87$ (95\% CI, 1.54 to 12.86)) and population growth rate $<25 \%(\mathrm{OR}=2.93(95 \% \mathrm{CI}, 1.51$ to 6.07$))$ and $>25 \%(\mathrm{OR}=3.74$ (95\% CI, 1.67 to 8.58$)$ ) were found to be significant predictors. The results also indicated a statistically significant and negative association between spatial accessibility score and unintentional residential fire-related injury (OR=0.90 (95\% CI, 0.80 to 0.99$))$.

\section{DISCUSSION}

This study measured spatial accessibility to fire protection services and its association with unintentional residential fires involving injury or death in Dallas City, Texas. Uneven spatial accessibility across the city was observed (figure 2 ). This implies that the interaction between demand and provision of fire protection services within the travel time threshold for first responders recommended by the NFPA standard was not uniformly distributed across the city. While the centre of the city showed relatively high spatial accessibility, areas with index scores below the citywide mean in the southwest, southeast and northeast parts of the city indicated two types of low spatial accessibility. The first type included areas with census block groups that had population densities higher than the city mean (3818 per square mile in 2015). In these areas, lower spatial accessibility (mean index score: 4.7 vs 5.2 ) was likely driven by a large number of populations to serve compared with the provision of services. The second type included areas with road network distances longer than 2.22 miles between their centroids and the nearest fire station, aligning to the radius of our catchment areas. These areas also indicated lower spatial accessibility (mean index score: 3.7 vs 5.0), reflecting low availability of fire stations due to distant locations.

When the multiple logistic regression analysis was carried out, spatial accessibility measurements demonstrated a statistically significant negative relationship with unintentional residential fire-related injury or death. Although its magnitude of odds ratios was relatively small compared with other risk factors, it highlights the 
possibility that improved spatial accessibility to fire protection services might play a role in decreasing potential risk in residential fire-related injury.

The analysis results for the risk factors related to fire characteristics, race and age were consistent with literature. As the elderly population has been known to be vulnerable to residential fire injury or death, our results additionally implied potential risks of living alone for seniors, likely caused by reduced mobility or physical impairment which may impede egress from a fire. ${ }^{36}$ While neighbourhood population density has been found to be connected to fire risk in urban areas, ${ }^{14}$ it did not show significant association with the risk of unintentional residential fire-related injury or death in our analysis. However, average population change rate over the recent 5 years (2010-2015) did indicate a statistically significant relationship. This is likely due to a population influx either leading to housing structure crowding or to an increase in groups of population that are vulnerable to fire injury. As the city's population grows, population change rate and distribution of spatial accessibility scores can jointly be used to identify potential areas in need of additional provision for fire stations. In figure 3, census block groups with spatial accessibility score lower than the city mean and average population growth rate $>25 \%$ were generally observed in southwest and southeast service areas, as well as near city borders in south central area.

The study findings should be interpreted in the context of the limitations to our study. While the presence of functional smoke detectors has been found to play a substantial role in preventing fire injuries, ${ }^{2}{ }^{37}$ our data did not contain sufficient information on this factor to include in our analysis. Additionally, the severity of injury, including and up to death, was not distinguished due to a considerably small number of cases resulting in injury or death. Thus, the analysis focused exclusively on whether or not a residential fire involved injury or death. In addition, capacity of fire protection services in this study related to the presence of a fire engine at a fire station. Individual characteristics of firefighting apparatus or size of

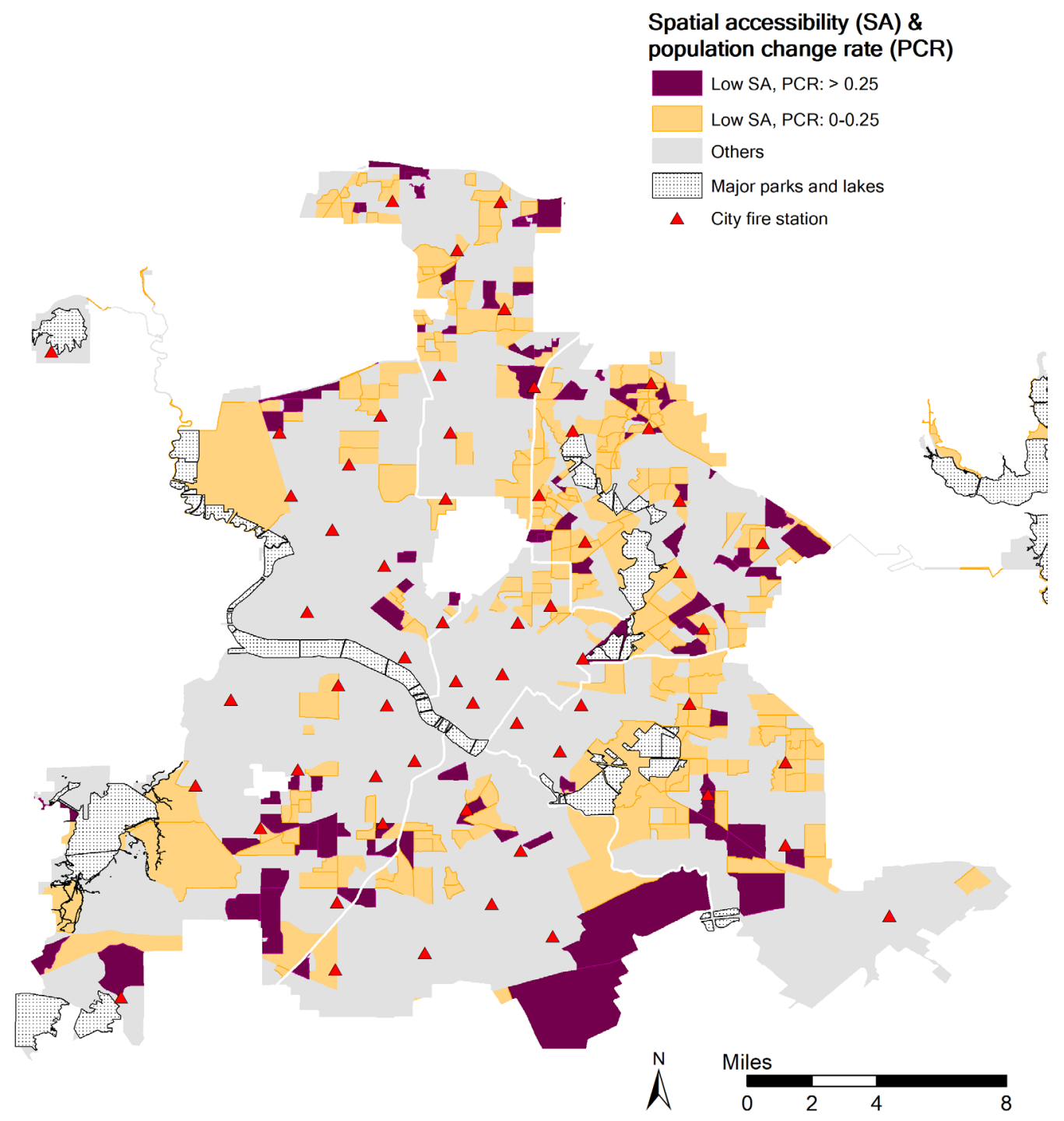

Figure 3 Areas with low spatial accessibility score and average population change rate from 2010 to 2015. 
firefighting staff are likely to be varied particularly among adjacent cities, but this falls outside the scope of the analysis and was not taken into account when estimating spatial accessibility from population centres located near the study area border. Although the study excluded arson cases and fires with unknown causes, individual factors that may have contributed to injuries or deaths such as proximity to ignition or intoxication were not taken into account. Finally, generalisability is limited in that the findings were based on a sample within one city.

To the authors' knowledge, this is the first study to assess distribution of spatial accessibility to fire protection services as a risk factor for injury or death caused by unintentional residential fire incidents. Although this study does not reveal specific causal links between low spatial accessibility to fire protection services and unintentional residential fire-related injury risk, the findings can be useful in contributing to guidelines for the city management regarding identifying potential areas that additional fire stations can adequately serve. The implication of the study is that city management can make more informed decisions locating public service provisions such as fire stations by considering the distribution of spatial accessibility in addition to housing and population density information, which is generally the primary driver of such decisions.

Contributors SM developed the research idea, obtained the data and conducted the data analyses. SM and DK refined the study design. DK and CKL supervised the study. SM wrote the majority of the manuscript and DK and CKL contributed to the method and discussion parts. All authors critically reviewed and approved the final manuscript.

Funding This work was supported by Incheon National University International Cooperative Research Grant in 2015.

Disclaimer The depiction of boundaries on the map(s) in this article do not imply the expression of any opinion whatsoever on the part of BMJ (or any member of its group) concerning the legal status of any country, territory, jurisdiction or area or of its authorities. The map(s) are provided without any warranty of any kind, either express or implied.

Competing interests None declared.

Patient consent for publication Not required.

Ethics approval This study used only publicly available data and it was granted by the Institutional Review Board at the University of Texas at Dallas (IRB 17-74).

Provenance and peer review Not commissioned; externally peer reviewed.

Data sharing statement There is no additional unpublished data from the study.

Open access This is an open access article distributed in accordance with the Creative Commons Attribution Non Commercial (CC BY-NC 4.0) license, which permits others to distribute, remix, adapt, build upon this work non-commercially, and license their derivative works on different terms, provided the original work is properly cited, appropriate credit is given, any changes made indicated, and the use is non-commercial. See: http://creativecommons.org/licenses/by-nc/4.0/.

\section{REFERENCES}

1. Jennings CR. Social and economic characteristics as determinants of residential fire risk in urban neighborhoods: A review of the literature. Fire Saf J 2013;62:13-19.

2. Istre GR, McCoy MA, Osborn L, et al. Deaths and injuries from house fires. N Engl J Med 2001;344:1911-6.

3. Stylianou N, Buchan I, Dunn KW. A review of the international Burn Injury Database (iBID) for England and Wales: descriptive analysis of burn injuries 2003-2011. BMJ Open 2015;5:e006184-10.
4. Edelman LS. Social and economic factors associated with the risk of burn injury. Burns 2007;33:958-65.

5. Bruck D, Ball M, Thomas IR. Fire fatality and alcohol intake: analysis of key risk factors. J Stud Alcohol Drugs 2011;72:731-6.

6. Diekman ST, Ballesteros MF, Berger LR, et al. Ecological level analysis of the relationship between smoking and residential-fire mortality. Inj Prev 2008;14:228-31.

7. Merkin SS, Diez Roux AV, Coresh J, et al. Individual and neighborhood socioeconomic status and progressive chronic kidney disease in an elderly population: The Cardiovascular Health Study. Soc Sci Med 2007;65:809-21.

8. Singh GK, Siahpush M, Kogan MD, et al. built environments, and childhood obesity. Health Affs 2010;29:503-12.

9. Hannon L, Shai D. The truly disadvantaged and the structural covariates of fire death rates. Soc Sci J 2003;40:129-36.

10. Guagliardo MF. Spatial accessibility of primary care: concepts, methods and challenges. Int J Health Geogr 2004;3.1.1.

11. Michimi A, Wimberly MC. Associations of supermarket accessibility with obesity and fruit and vegetable consumption in the conterminous United States. Int J Health Geogr 2010;9:49.

12. Luo W, Qi Y. An enhanced two-step floating catchment area (E2SFCA) method for measuring spatial accessibility to primary care physicians. Health Place 2009;15:1100-7.

13. Challands N. The Relationships Between Fire Service Response Time and Fire Outcomes. Fire Technol 2010;46:665-76.

14. Lambert TE, Srinivasan AK, Katirai M. Ex-Urban Sprawl and Fire Response in the United States. J Econ Issues 2012;46:967-88.

15. Texas Department of Insurance. Fires in Texas 2014, Annual Fire Statistics. Texas Fire Incident Reporting System: State Fire Marshal's Office, Texas Department of Insurance. 2015.

16. Dallas Fire-Rescue Department. Fire stations. 2018 http://www. dallasfirerescue.com/fire_stations.html (accessed February 10, 2018).

17. U.S. Census Bureau. American Community Survey (ACS). 2017 https://www.census.gov/programs-surveys/acs/ (accessed February 1, 2018).

18. U.S. Fire Administration. Fire Statistics. 2017 https://www.usfa.fema. gov/data/statistics/ (accessed January 1, 2018).

19. Wang F, Measurement WF. Measurement, Optimization, and Impact of Health Care Accessibility: A Methodological Review. Ann Assoc Am Geogr 2012;102:1104-12.

20. Guo Y, Chang S-S, Chen M, et al. Do Poorer Areas Have Poorer Access to Services in Hong Kong? A Small-Area Analysis Based on Multiple Spatial Accessibility Indicators. Soc Indic Res 2018;138:1-21.

21. Luo W. Using a GIS-based floating catchment method to assess areas with shortage of physicians. Health Place 2004;10:1-11.

22. Delamater PL. Spatial accessibility in suboptimally configured health care systems: a modified two-step floating catchment area (M2SFCA) metric. Health Place 2013;24:30-43.

23. Bauer J, Groneberg DA. Measuring Spatial Accessibility of Health Care Providers - Introduction of a Variable Distance Decay Function within the Floating Catchment Area (FCA) Method. PLoS One 2016;11:e0159148

24. Luo W, Wang F. Measures of Spatial Accessibility to Health Care in a GIS Environment: Synthesis and a Case Study in the Chicago Region. Environment and Planning B: Planning and Design 2003;30:865-84.

25. Campbell E. Communications and technology division: Dallas Fire-Rescue Department. 2009 http://www3.dallascityhall.com/ committee_briefings/briefings0809/PUB_CommunicationTec hnology_080309.pdf (accessed February 1, 2018).

26. National Fire Protection Association. NFPA 1710, standard for the organization and deployment of fire suppression operations, emergency medical operations, and special operations to the public by career fire departments: National Fire Protection Association. 2010.

27. Texas Sof. Transportation code; title 7. vehicles and traffic; subtitle C rules of the road; . chapter 545. operation and movement of vehicles 1995 http://www.statutes.legis.state.tx.us/Docs/TN/htm/TN.545.htm (accessed February 10, 2018)

28. Shahid R, Bertazzon S, Knudtson ML, et al. Comparison of distance measures in spatial analytical modeling for health service planning. BMC Health Serv Res 2009;9:1):1.

29. Mao L, Nekorchuk D. Measuring spatial accessibility to healthcare for populations with multiple transportation modes. Health Place 2013;24:115-22.

30. Nasseh K, Eisenberg Y, Vujicic M. Geographic access to dental care varies in Missouri and Wisconsin. J Public Health Dent 2017;77:197-206. 
31. Vo A, Plachkinova M, Bhaskar R. Assessing healthcare accessibility algorithms: A comprehensive investigation of two-step floating catchment methodologies family. 2015.

32. U.S. Census Bureau. Census Geocoder. 2017 https://www. census.gov/geo/maps-data/data/geocoder.html (accessed February 1, 2018).

33. U.S. Fire Administration National Fire Data Center. National fire incident reporting system - complete reference guide: U. S. Fire Administration 2015

34. Hasofer AM, Thomas I. Analysis of fatalities and injuries in building fire statistics. Fire Saf J 2006;41:2-14.
35. Bureau of Health Workforce Health Resources and Services Administration (HRSA). Designated health professional shortage areas statistics: U. S. Department of Health \& Human Services 2018 https://ersrs.hrsa.gov/ReportServer?/HGDW Reports/BCD HPSA/ BCD_HPSA_SCR50_Smry\&rs:Format=PDF (accessed February 20, 2018).

36. Harpur A, Boyce K, McConnel N. An Investigation into the Circumstances Surrounding Elderly Dwelling Fire Fatalities and the Barriers to Implementing Fire Safety Strategies among this Group. Fire Safety Science 2014;11:1144-59.

37. Ahrens M. Home Smoke Alarms: The Data as Context for Decision. Fire Technol 2008;44:313-27. 